\title{
AN483, a new anti-MRSA compound from Streptomyces sp.
}

\author{
Yun J Kwon ${ }^{1}$, Mi-Jin Sohn ${ }^{1}$, Hiroyuki Koshino ${ }^{2}$, Chang-Jin Kim $^{3}$ and Won-Gon Kim ${ }^{1}$ \\ The Journal of Antibiotics (2016) 69, 762-764; doi:10.1038/ja.2015.143; published online 13 January 2016
}

Gram-positive eubacteria are representative of pathogenic microorganisms. Especially, Staphylococcus aureus is the most clinically important of these pathogens because of its exceptional virulence, stress tolerance and capacity to accumulate antimicrobial resistances. ${ }^{1,2}$ Antibiotic-resistant strains of pathogenic bacteria are increasingly prevalent in hospitals and the community. Of antibiotic-resistant pathogens, the one that has gained the most attention is methicillinresistant $S$. aureus (MRSA) because of its high frequency of infection as well as its resistance to many other antibiotics. ${ }^{3,4}$ Overall, in the United States and the United Kingdom, 40-60\% of nosocomial S. aureus strains are methicillin resistant. The increased use of vancomycin, the last anti-MRSA antibiotic in the last century, resulted in the prevalence of vancomycin-resistant Enterococcus. Although some anti-MRSA drugs such as linezolid and daptomycin have been introduced in recent years, ${ }^{5}$ new classes of anti-MRSA agents are still needed.

In the course of our continued screening for new anti-MRSA agents from microbial resources, ${ }^{6}$ a new anthracenone-type antibiotic (1) was isolated from liquid fermentation cultures of Streptomyces sp. AN100483 (Figure 1). The anthracenone-type compounds are rare metabolites. To the best of our knowledge, only three anthracenonetype compounds have been reported that include WS9761, ${ }^{7}$ Q6916Z ${ }^{8}$ and dimeric oxanthromicin. ${ }^{9}$ Especially, compound $\mathbf{1}$ is chlorinated unlike other compounds. In this paper, we report the fermentation, isolation, structure determination and antibacterial activity of $\mathbf{1}$.

The actinomycetal strain AN100483 was isolated from a soil sample that was collected at Colocasia esculenta field, Baekam Mountain, Gyeongsangbuk-do, Korea, and identified as Streptomyces sp. based on $16 \mathrm{~S}$ DNA sequence. Fermentation was carried out in a liquid culture medium containing soluble starch $1 \%$, glucose $2 \%$, soybean meal $2.5 \%$, beef extract $0.1 \%$, yeast extract $0.4 \%, \mathrm{NaCl} 0.2 \%, \mathrm{~K}_{2} \mathrm{HPO}_{4}$ $0.025 \%$ and $\mathrm{CaCO}_{3}$ 0.2\% (adjusted to $\mathrm{pH} 7.2$ before sterilization). A portion of the strain AN100483 from a mature plate culture was inoculated into a 500-ml Erlenmeyer flask containing $80 \mathrm{ml}$ of the above sterile seed liquid medium and cultured on a rotary shaker (150 r.p.m.) at $28^{\circ} \mathrm{C}$ for 3 days. For the production of an active compound, $5 \mathrm{ml}$ of the seed culture were transferred into $500 \mathrm{ml}$ Erlenmeyer flasks containing $100 \mathrm{ml}$ of the above medium, and cultivated on a rotary shaker (150 r.p.m.) for 10 days at $28^{\circ} \mathrm{C}$. After incubation, the fermented liquid cultures (3l) were extracted with $80 \%$ acetone. The acetone extracts were concentrated in vacuo to an aqueous solution, which was then extracted with an equal volume of EtOAc three times. The EtOAc extract $(1.2 \mathrm{~g})$ was subjected to silica gel $(56 \times 200 \mathrm{~mm}$, Merck Art No. 7734.9025$)$ column chromatography, followed by stepwise elution with $\mathrm{CHCl}_{3}-\mathrm{MeOH}$ (100:1, 50:1, 25:1). Each fraction was tested for anti-MRSA activity. The active fractions eluted with $\mathrm{CHCl}_{3}-\mathrm{MeOH}$ (50:1) were pooled and concentrated in vacuo. The resultant residue $(285 \mathrm{mg})$ was purified by preparative HPLC equipped with Waters 510 HPLC pump and Waters 996 Photodiode Array Detector. The reverse phase HPLC column $\left(20 \times 150 \mathrm{~mm}\right.$, YMC C18) was eluted with $\mathrm{CH}_{3} \mathrm{CN}-\mathrm{H}_{2} \mathrm{O}(65: 35)$ containing $0.035 \%$ trifluoroacetic acid at a flow rate of $6 \mathrm{ml}$ per min to afford $3.3 \mathrm{mg}$ of 1 with retention time of $28 \mathrm{~min}$.

The molecular formula of 1 was determined as $\mathrm{C}_{17} \mathrm{H}_{15} \mathrm{ClO}_{4}$ on the basis of the HRESI-MS [(M - H $)^{-}, 317.0564 \mathrm{~m} / z(-1.6$ m.m.u. error $\left.)\right]$ in combination with the ${ }^{1} \mathrm{H}$ and ${ }^{13} \mathrm{C}$ NMR data (Table 1). Together with HRESI-MS data, the $\mathrm{M}+2$ peak having approximately one-third intensity of the molecular ion peak indicated the presence of a chlorine atom. Compound 1 gave characteristic UV maxima at 231, 279, 310 and $348 \mathrm{~nm}$. IR absorptions of 1 at 1687 and $3448 \mathrm{~cm}^{-1}$ suggested the presence of carbonyl and hydroxyl moieties, respectively.

The ${ }^{1} \mathrm{H}$ and ${ }^{13} \mathrm{C}$ NMR data (Table 2) supported by HMQC data suggested the presence of three aromatic methines $\left(\delta_{\mathrm{H}} 6.37, \mathrm{~s}, \delta_{\mathrm{C}}\right.$ $102.9 ; \delta_{\mathrm{H}} 6.78$, brs, $\delta_{\mathrm{C}} 118.6$; and $\delta_{\mathrm{H}} 6.92$, brs, $\left.\delta_{\mathrm{C}} 111.8\right)$, an aromatic methyl $\left(\delta_{\mathrm{H}} 2.74, \mathrm{~s}, \delta_{\mathrm{C}} 24.5\right)$, a $\mathrm{CHCH}_{3}\left(\delta_{\mathrm{H}} 1.45, \mathrm{q}, J=6.6, \delta_{\mathrm{C}} 28.4\right.$ and $\left.\delta_{\mathrm{H}} 4.50, \mathrm{~d}, J=6.6, \delta_{\mathrm{C}} 39.3\right)$, a methoxy, nine $s p^{2}$ quaternary carbons $\left(\delta_{C} 164.8,164.5,160.8,152.5,146.9,146.0,122.5,111.7\right.$ and 110.9) and a ketone carbonyl $\left(\delta_{\mathrm{C}} 190.7\right)$. In the HMBC spectrum (Figure 2), the two aromatic methine protons at $\delta_{\mathrm{H}} 6.78(\mathrm{H}-7)$ and $\delta_{\mathrm{H}} 6.92(\mathrm{H}-5)$ have the long-range correlations with carbons at $\delta_{\mathrm{C}} 111.8(\mathrm{C}-5)$ and $\delta_{\mathrm{C}} 118.6(\mathrm{C}-7)$, respectively, and also with the $s p^{2}$ quaternary carbons at $\delta_{\mathrm{C}} 122.5(\mathrm{C}-8 \mathrm{a})$ and $\delta_{\mathrm{C}} 164.6(\mathrm{C}-6)$. In addition, the aromatic

${ }^{1}$ Superbacteria Research Center, Korea Research Institute of Bioscience and Biotechnology, Yusong, Daejeon, Republic of Korea; ${ }^{2}$ RIKEN Center for Sustainable Resources Science, Wako, Saitama, Japan and ${ }^{3}$ Industrial Bioresources Research Center, Korea Research Institute of Bioscience and Biotechnology, Yusong, Daejeon, Republic of Korea Correspondence: Dr W-G Kim, Superbacteria Research Center, Korea Research Institute of Bioscience and Biotechnology, Oeung-dong, Yusong, Daejeon 305-806, Republic of Korea.

E-mail: wgkim@kribb.re.kr

Received 1 November 2015; revised 6 December 2015; accepted 10 December 2015; published online 13 January 2016 
<smiles>COc1cc(C)c2c(c1)C(C)c1c(Cl)c(O)cc(O)c1C2=O</smiles>

Figure 1 Chemical structure of AN483 (1).

Table 1 Physico-chemical properties of 1

\begin{tabular}{|c|c|}
\hline Appearance & Reddish-yellow powder \\
\hline$[\alpha]_{D}$ & $+82.2(\mathrm{c} 0.1 \mathrm{MeOH})$ \\
\hline ESI-MS $(m / z)$ & $317(\mathrm{M}-\mathrm{H})^{-}, 319(\mathrm{M}+\mathrm{H})^{+}$ \\
\hline \multicolumn{2}{|l|}{ HRESI-MS $(\mathrm{m} / \mathrm{z})$} \\
\hline Found. & 317.0564 \\
\hline Calcd. & $317.0580(\mathrm{M}-\mathrm{H})^{-}$ \\
\hline Molecular formula & $\mathrm{C}_{17} \mathrm{H}_{15} \mathrm{ClO}_{4}$ \\
\hline UV $\lambda_{\max } \mathrm{nm}(\log \varepsilon)$ & 202 (4.54), 212 (sh 4.42), 231 (4.07), 243 (3.90), \\
\hline$(\mathrm{MeOH})$ & 279 (3.76), 310 (3.87), 348 (3.88) \\
\hline $\mathrm{IR}(\mathrm{KBr}) \gamma \mathrm{cm}^{-1}$ & $3448,2918,2850,1687,1603,1358,1258,1212$ \\
\hline
\end{tabular}

Table $2{ }^{1} \mathrm{H}$ and ${ }^{13} \mathrm{C}$ NMR spectral data for 1

\begin{tabular}{lcc}
\hline Position & $\delta_{H}\left(\right.$ mult., $\left.\mathrm{H}_{H}\right)$ & $\delta_{\mathrm{C}}$ \\
\hline 1 & & $160.8 \mathrm{C}$ \\
2 & $6.37(1 \mathrm{H}, \mathrm{s})$ & $102.9 \mathrm{CH}$ \\
3 & & $164.8 \mathrm{C}$ \\
4 & & $110.9 \mathrm{C}$ \\
$4 \mathrm{a}$ & & $146.9 \mathrm{C}$ \\
5 & $6.92(1 \mathrm{H}, \mathrm{brs})$ & $111.8 \mathrm{CH}$ \\
6 & & $164.5 \mathrm{C}$ \\
$6-\mathrm{CCH}_{3}$ & $3.90(3 \mathrm{H}, \mathrm{s})$ & $56.1 \mathrm{CH}$ \\
7 & $6.78(1 \mathrm{H}, \mathrm{brs})$ & $118.6 \mathrm{CH}$ \\
8 & & $146.0 \mathrm{C}$ \\
$8 \mathrm{a}$ & & $122.5 \mathrm{C}$ \\
9 & & $190.7 \mathrm{C}$ \\
$9 a$ & & $111.7 \mathrm{C}$ \\
10 & & $39.3 \mathrm{CH}$ \\
$10 a$ & $4.50(1 \mathrm{H}, \mathrm{q}, 6.6)$ & $152.5 \mathrm{C}$ \\
$1^{\prime}$ & & $28.4 \mathrm{CH}_{3}$ \\
$1^{\prime \prime}$ & $1.45(3 \mathrm{H}, \mathrm{d}, 6.6)$ & $24.5 \mathrm{CH}_{3}$ \\
\hline
\end{tabular}

${ }^{1} \mathrm{H}$ and ${ }^{13} \mathrm{C}$ NMR spectral data were measured at 500 and $125 \mathrm{MHz}$, respectively, in $\mathrm{CD}_{3} \mathrm{OD}$. The assignments were aided by HMQC, HMBC and NOESY.

methyl protons at $\delta_{\mathrm{H}} 2.74\left(\mathrm{H}_{3}-1 "\right)$ were long-ranged coupled to the $s p^{2}$ quaternary carbon at $\delta_{\mathrm{C}} 146.0(\mathrm{C}-8), \mathrm{C}-7$ and C-8a. These spectral data suggested the presence of an 1,2,3,5-tetrasubstituted benzene with the methyl and the methoxy substituents at $\mathrm{C}-1$ and $\mathrm{C}-5$, respectively. The methyl protons $\left(\mathrm{H}_{3}-1\right.$ ') of the $\mathrm{CHCH}_{3}$ group have the $\mathrm{HMBC}$ correlations with the $s p^{2}$ quaternary carbons at $\delta_{\mathrm{C}} 146.9(\mathrm{C}-4 \mathrm{a})$ and $\delta_{\mathrm{C}}$ 152.5 (C-10a), and the methine proton $(\mathrm{H}-10)$ of the $\mathrm{CHCH}_{3}$ group was long-ranged coupled to the $s p^{2}$ quaternary carbons at $\delta_{\mathrm{C}} 111.7$ (C-9a) and $\delta_{\mathrm{C}} 110.9$ (C-4), C-4a, C-5, C-8a and C-10a. In addition, the $\mathrm{HMBC}$ correlations from the remaining aromatic proton at $\delta_{\mathrm{H}}$

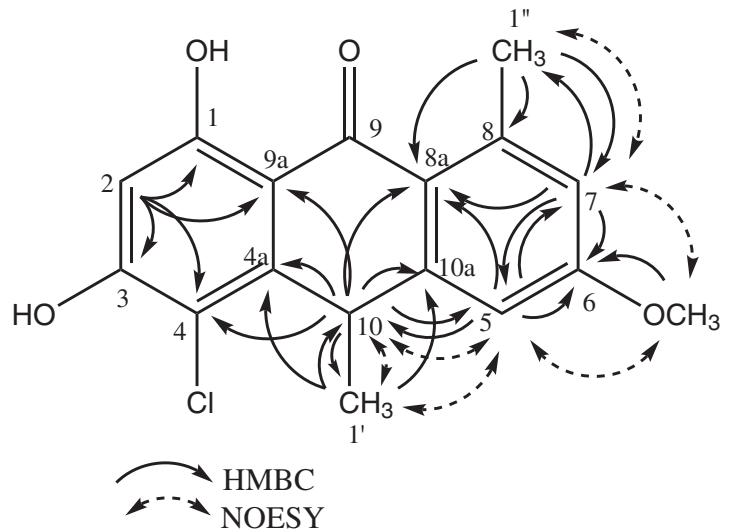

Figure $2 \mathrm{HMBC}$ and NOE correlations of $\mathbf{1}$.

$6.37(\mathrm{H}-2)$ to the oxygenated $s p^{2}$ quaternary carbons at $\delta_{\mathrm{C}} 160.8(\mathrm{C}-1)$ and $\delta_{\mathrm{C}} 164.8(\mathrm{C}-3), \mathrm{C}-4$ and $\mathrm{C}-9 \mathrm{a}$. This spectral data suggested the presence of a 1,2,3,4,5-pentasubstituted benzene that was linked to the 1,2,3,5-tetrasubstituted benzene by the $\mathrm{CHCH}_{3}$ group between $\mathrm{C}-4 \mathrm{a}$ and C-10a. This was confirmed by the NOEs between $\mathrm{H}-10 / \mathrm{H}_{3}-1$ ' and $\mathrm{H}-5$ (Figure 2). Also the presence of the methyl and methoxy at C-8 and $\mathrm{C}-6$, respectively, was confirmed by NOEs from $6-\mathrm{OCH}_{3}$ to $\mathrm{H}-5 / \mathrm{H}-7$, and from $\mathrm{H}_{3}-1$ " to $\mathrm{H}-7$. Considering the low-field-shifted chemical shifts of C-4a and C-10a, the ketone carbon (C-9) should be located between C-8a and C-9a. Also considering the chemical shifts of C-4 and the molecular formula, C-4 should be chlorinated. Thus, the structure of 1 was determined as shown in Figure 1.

The antibacterial activity of $\mathbf{1}$ was evaluated with serial two-fold dilutions starting with $128 \mu \mathrm{g} \mathrm{ml}^{-1}$ according to our previously reported method. ${ }^{10}$ Compound $\mathbf{1}$ exhibited antibacterial activity against S. aureus RN4220, methicillin-resistant S. aureus (MRSA; S. aureus CCARM 3167 and S. aureus CCARM 3506), and quinolone-resistant $S$. aureus (S. aureus CCARM 3505 and S. aureus CCARM 3519) with MIC of $32 \mu \mathrm{g} \mathrm{ml}^{-1}$. As a positive control, ciprofloxacin showed antibacterial activity against S. aureus RN4220, MRSA (S. aureus CCARM 3167 and S. aureus CCARM 3506), and quinolone-resistant $S$. aureus (S. aureus CCARM 3505 and S. aureus CCARM 3519) with MIC of $0.125,4$ and $128 \mu \mathrm{g} \mathrm{ml}^{-1}$, respectively. Compound 1 also showed antibacterial activity against other pathogenic bacteria including Enterococcus faecalis KCTC 5191 and Bacillus cereus KCTC 1661 with MIC of $32 \mu \mathrm{g} \mathrm{ml}^{-1}$. However, 1 did not have antibacterial activity against some gram-negative bacteria including Pseudomonas aeruginosa and Acetobacter baumannii at $128 \mu \mathrm{g} \mathrm{ml}^{-1}$.

Compound $\mathbf{1}$ is a new chlorinated compound containing the anthracenone skeleton. The anthracenone antibiotics are rare metabolites since, to the best of our knowledge, only three compounds have been reported that include WS9761, Q6916Z and dimeric oxanthromicin which have been isolated from Streptomyces sp. and Actinomadura sp. WS9761 has been reported as an androgen-receptor antagonist. ${ }^{7}$ Q6916Z has been known to inhibit phospholipase A2. ${ }^{8}$ Oxanthromicin, a dimeric compound, has been reported to show antimicrobial activity against dermatophytic fungi, Candida albicans and S. aureus. ${ }^{9}$ Oxathromicin glycosides such as adxanthromycin A and $\mathrm{B}$ have been reported to inhibit cell division. ${ }^{11-13}$

In summary, AN483 is a new chlorinated anthracenone, a rare metabolite, isolated from a strain of Streptomyces sp. AN100483. AN483 showed antibacterial activity against gram-positive pathogenic bacteria including MRSA and QRSA. 


\section{CONFLICT OF INTEREST}

The authors declare no conflict of interest.

\section{ACKNOWLEDGEMENTS}

This work was supported by the Basic Science Research Program through the National Research Foundation of Korea (NRF) funded by the Ministry of Education, Science and Technology (2012R1A2A2A01014821) and KRIBB Research Initiative Program, Republic of Korea. We express our thanks to Korea Basic Science Institute for the NMR measurements.

1 Kumar, K. \& Chopra, S. New drugs for methicillin-resistant Staphylococcus aureus: an update. J. Antimicrob. Chemother. 68, 1465-1470 (2013).

2 Chambers, H. F. \& Deleo, F. R. Waves of resistance: Staphylococcus aureus in the antibiotic era. Nat. Rev. Microbiol. 7, 629-641 (2009).

3 Shlaes, D. M. \& Spellberg, B. Overcoming the challenges to developing new antibiotics. Curr. Opin. Pharmacol. 12, 522-526 (2012).

4 Fischbach, M. A. \& Walsh, C. T. Antibiotics for emerging pathogens. Science $\mathbf{3 2 5}$ 1089-1093 (2009).
5 Butler, M. S., Blaskovich, M. A. \& Cooper, M. A. Antibiotics in the clinical pipeline in 2013. J. Antibiot. (Tokyo) 66, 571-591 (2013).

6 Zheng, C. J., Yu, H. E., Kim, E. H., Kim, W. G. \& Viridicatumtoxin, B. a new anti-MRSA agent from Penicillium sp. FR11. J. Antibiot. (Tokyo) 61, 633-637 (2008).

7 Hori, Y. et al. WS9761 A and B: new non-steroidal androgen-receptor antagonists produced by a Streptomyces. J. Antibiot. (Tokyo) 46, 1901-1903 (1993).

8 Tanaka, K. et al. ((Yamanouchi Pharma Co Ltd, Japan; Pii Teii Karube Fuaruma).). Phospholipase A2 inhibitors containing Q-6916. JP 1991-315514 07017905. (1995)

9 Patel, M. et al. Oxanthromicin, a novel antibiotic from Actinomadura. J. Antibiot. (Tokyo) 37, 413-415 (1984).

10 Kwon, Y. J., Kim, H. J. \& Kim, W. G. Complestatin exerts antibacterial activity by the inhibition of fatty acid synthesis. Biol. Pharm. Bull. 38, 715-721 (2015).

11 Nakano, T., Koiwa, T., Takahashi, S. \& Nakagawa, A. Adxanthromycins A and B, new inhibitors of ICAM-1/LFA-1 mediated cell adhesion molecule from Streptomyces sp. NA-148. I. Taxonomy, production, isolation and biological activities. J. Antibiot. (Tokyo) 53, 12-18 (2000).

12 Koiwa, T. et al. Adxanthromycin: a new inhibitor of ICAM-1/LFA-1 mediated cell adhesion from Streptomyces sp. NA-148. J. Antibiot. (Tokyo) 52, 198-200 (1999).

13 Takahashi, $S$. et al. Adxanthromycins A and B, new inhibitors of ICAM-1/LFA-1 mediated cell adhesion molecule from Streptomyces sp. NA-148. II. Physicochemical properties and structure elucidation. J. Antibiot. (Tokyo) 53, 163-170 (2000).

Supplementary Information accompanies the paper on The Journal of Antibiotics website (http://www.nature.com/ja) 